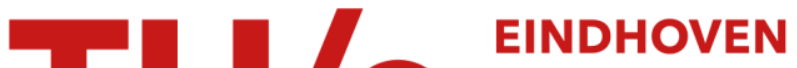 UNIVERSITY OF TECHNOLOGY
}

\section{Algorithms for arrival time estimation of partial discharge pulses in cable systems}

\section{Citation for published version (APA):}

Wagenaars, P., Wouters, P. A. A. F., Wielen, van der, P. C. J. M., \& Steennis, F. (2008). Algorithms for arrival time estimation of partial discharge pulses in cable systems. In Electrical Insulation (ISEI) 2008. Conference Record of the 2008 international symposium, 9-12 June 2008 Vancouver, Canada (pp. 20-23). Institute of Electrical and Electronics Engineers. https://doi.org/10.1109/ELINSL.2008.4570425

DOI:

10.1109/ELINSL.2008.4570425

Document status and date:

Published: 01/01/2008

\section{Document Version:}

Publisher's PDF, also known as Version of Record (includes final page, issue and volume numbers)

\section{Please check the document version of this publication:}

- A submitted manuscript is the version of the article upon submission and before peer-review. There can be important differences between the submitted version and the official published version of record. People interested in the research are advised to contact the author for the final version of the publication, or visit the $\mathrm{DOI}$ to the publisher's website.

- The final author version and the galley proof are versions of the publication after peer review.

- The final published version features the final layout of the paper including the volume, issue and page numbers.

Link to publication

\section{General rights}

Copyright and moral rights for the publications made accessible in the public portal are retained by the authors and/or other copyright owners and it is a condition of accessing publications that users recognise and abide by the legal requirements associated with these rights.

- Users may download and print one copy of any publication from the public portal for the purpose of private study or research.

- You may not further distribute the material or use it for any profit-making activity or commercial gain

- You may freely distribute the URL identifying the publication in the public portal.

If the publication is distributed under the terms of Article 25fa of the Dutch Copyright Act, indicated by the "Taverne" license above, please follow below link for the End User Agreement:

www.tue.nl/taverne

Take down policy

If you believe that this document breaches copyright please contact us at:

openaccess@tue.nl

providing details and we will investigate your claim. 


\section{Algorithms for Arrival Time Estimation of Partial Discharge Pulses in Cable Systems}

\author{
P. Wagenaars and P.A.A.F. Wouters \\ Eindhoven University of Technology \\ P.O. Box 513 \\ 5600 MB Eindhoven, The Netherlands
}

\author{
P.C.J.M. van der Wielen and E.F. Steennis \\ KEMA \\ P.O. Box 9035 \\ 6800 ET Arnhem, The Netherlands
}

\begin{abstract}
Partial discharge (PD) detection and location in cable systems is a valuable tool for the estimation of the condition of the system. Accurate localization of the PD origin, based on arrival times, is required for the identification and assessment of the defect. This paper evaluates different time-of-arrival algorithms to determine which method yields most accurate location under different circumstances. These methods are based on trigger level, Akaike Information Criterion (AIC), energy criterion, Gabor's signal centroid and phase in frequency domain. Several criteria are defined by which the algorithms are evaluated. These criteria include the sensitivity to the noise level, the sensitivity to the pulse shape and others. The methods are tested on a medium-voltage cable system by injecting PD pulses in a cable with a joint at a known location. Each algorithm is applied to the measured pulses and the resulting location is compared with the known location. From the result the methods using the energy criterion and the phase are preferred.
\end{abstract}

\section{INTRODUCTION}

For a condition based maintenance strategy a method to assess the condition of a cable system is required. Partial discharge (PD) diagnostics is such a method. During PD measurements it is essential to determine the origin of the discharges to estimate the likely defect type and severity. Furthermore, it is only possible to replace parts in a costeffective manner if the defect locations are known.

The accuracy of defect location depends on the accuracy of the time-of-arrival estimate of each PD pulse and how accurate the propagation time of the entire cable is known. The methods to estimate the time-of-arrival analyzed in this paper are generally applicable to different PD location systems. However, our main interest concerns online application ([1]-[4]) with its obvious important advantages, but also its inherent additional complications. Ring Main Units (RMUs) or substations form a non-matching load impedance $\left(Z_{\text {load }}\right)$ and distort the pulse shape of both PD signals and injected signals at the cable end. Furthermore, when a cable remains in service it also is connected to the rest of the grid. Therefore, the measurements are impeded with higher noise and disturbance levels.

PD location in cable systems can be achieved with a single sensor if the far end is disconnected, or with two sensors (one at each cable end) if the cable is in normal operation (see [1]). Both methods need to estimate the total propagation time of the cable $\left(t_{c}\right)$ and the time-of-arrival $\left(t_{o \alpha}\right)$ of PD pulses in order to locate the origins of the PDs. The propagation time $t_{c}$ is determined using the time-of-arrival of injected pulses and their responses.

A set of evaluation criteria are defined in section II on basis of which five location techniques, described in section III, are evaluated. In this paper the methods are evaluated using experiments (section IV). An analytical comparison together with simulations can be found in [5].

\section{EVALUATION CRITERIA}

In order to make a well-founded comparison of the strong and weak points of each method a set of evaluation criteria is defined on which the methods are judged. The following criteria are used:

- Independent of noise level and spectrum.

- Independent of pulse shape and amplitude.

- Independent of length of recorded signal.

- Independent of the pulse location (in time) in the record.

- Insensitive to reflections of the main pulse on joints and RMUs.

- Accurate location of PD origin. For PD diagnostics on power cables a location accuracy of $1 \%$ of the cable length is usually considered to be sufficient.

A $t_{o a}$-method that meets all these criteria would be ideal, but even if not all criteria are met under all conditions, the method can be useful in specific situations.

\section{TIME-OF-ARRIVAL METHODS}

The five $t_{o a}$-methods are briefly described in the following sections. A more detailed description can be found in [5]. The following definitions are used in the following sections:

$x_{k} \quad$ recorded signal, $x_{k}=s_{k}+n_{k}$ with

$s_{k} \quad$ noise-free pulse signal

$n_{k} \quad$ additive, uncorrelated Gaussian noise

$k \quad$ index ranging from 1 to $N$

$N \quad$ number of samples in signal

$E_{x}, E_{s}, E_{n}$ energy in $x_{k}, s_{k}$ and $n_{k}\left(E_{x}=\sum_{k=1}^{N} x_{k}^{2}\right)$

$P_{x}, P_{s}, P_{n}$ mean power of $x_{k}, s_{k}$ and $n_{k}\left(P_{x}=E_{x} / N\right)$

\section{A. Trigger level method}

The trigger level method positions $t_{o \alpha}$ at the time at which the signal $x_{k}$ exceeds a certain threshold level $x_{t h r e s}$. This is a 
straightforward method that can easily be implemented and is therefore used in many PD detection systems. The threshold level is chosen relative to the noise level, making it always as low as the noise permits without too many false triggers:

$$
x_{\text {thres }}=m \cdot \sqrt{P_{n}}
$$

where $m$ is a parameter chosen by the user. In this paper the value $m=5$ is used for all simulations. In Fig. $1 \mathrm{a}$ a recorded pulse is plotted together with the threshold $x_{\text {thres }}$.

\section{B. Akaike Information Criterion method}

The Akaike Information Criterion (AIC) is a measure of the goodness of fit of a statistical model to a set of observations. It can be used to estimate the arrival time of PD pulses [6]. This method defines the curve $A I C_{k}$ as:

$$
A I C_{k}=k \cdot \ln \left(\sigma_{1, k}^{2}\right)+(N-k-1) \cdot \ln \left(\sigma_{k+1, N}^{2}\right)
$$

where $\sigma_{m, n}^{2}$ the variance of signal $x_{k}$ from index $m$ up to and including index $n$. The value $A I C_{k}$ is calculated for each sample in the signal $x_{k}$. The $t_{o a}$ is the global minimum of all $A I C_{k}$ values. In order to prevent ambiguous results the signal is cropped such that the pulse onset occurs in the second half of the signal, as suggested in [7]. Fig. 1b shows a signal and its corresponding $A I C_{k}$ curve.

\section{Energy criterion method}

The energy criterion (EC) method is based on the energy content of the signal. This method combines the partial signal energy with a negative trend [6]. The signal $E C_{k}$ is defined as:

$$
E C_{k}=\sum_{i=1}^{k} x_{i}^{2}-k \cdot P_{x}
$$

The value $E C_{k}$ is calculated for $k$ ranging for 1 to $N$. The global minimum of all $E C_{k}$ values coincides with the $t_{o a}$. Fig. $1 \mathrm{c}$ shows a PD pulse along with the $E C_{k}$ curve.

\section{Gabor centroid method}

Gabor defines the "epoch" of order 1 of a signal [8]. Assuming that the signal is real, converting it to time-discrete form and adding two extra terms to remove noise-dependency this epoch is defined as:

$$
t_{o a, g}=\frac{\sum_{k=1}^{N} t_{k} x_{k}^{2}-P_{n} \sum_{k=1}^{N} t_{k}}{\sum_{k=1}^{N} x_{k}^{2}-P_{n} \cdot N}
$$

where $t_{k}$ is the time corresponding to index $k$. In Fig. 1d a PD pulse is plotted and $t_{a a, g}$ is marked.

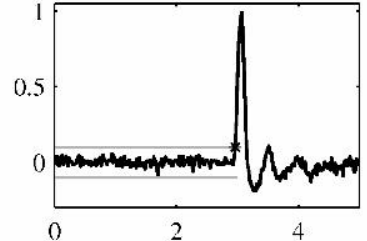

(a) Threshold

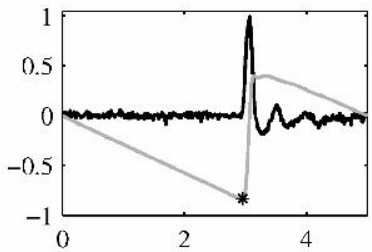

(c) Energy criterion

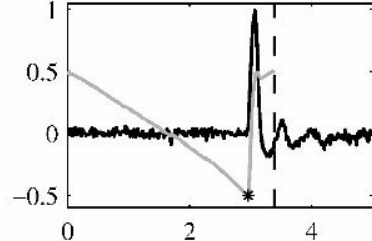

(b) AIC

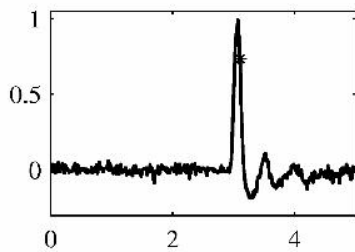

(d) Gabor
Fig. 1. Example of recorded pulse with four $t_{o x}$-methods applied. Time axes are in $\mu$ s. Black line: recorded PD signal, gray line: threshold ${ }^{(a)} /$ nor malized $\&$ shifted AIC curve ${ }^{(b)} /$ normalized EC curve ${ }^{(c)}$, *: time-of-arrival, and dashed line: end of record used for AIC analysis.

\section{E. Phase method}

The phase method converts the recorded signal $x_{k}$ to frequency domain $(X(\omega))$ and retrieves the phase for a chosen frequency. This phase can be interpreted as a time delay $(\tau)$. Unfortunately, due to the periodicity of $2 \pi$ the phase is ambiguous:

$$
\tau=\frac{-\angle X\left(\omega_{c}\right)}{\omega_{c}}+\frac{m \cdot 2 \pi}{\omega_{c}}
$$

where $m$ an unknown integer and $\omega_{c}$ is a chosen frequency (in $\mathrm{rad} / \mathrm{s}$ ) for which the delay is calculated. For consistency, $\omega_{c}$ must be the same for all measurements. Taking the average over a small frequency range around $\omega_{c}$ reduces the sensitivity to noise and reflections in the signal. The periodicity problem can be solved by applying a (negative) time delay $\tau_{c h}$ to $X(\omega)$ first. This can be achieved using: $X_{\mathrm{ch}}(\omega)=X(\omega) \cdot \exp \left(\mathrm{j} \omega \tau_{c h}\right)$. The delay $\tau_{c h}$ must be chosen such that the phase does no longer wrap around (jump from $-\pi$ to $\pi$, or vice versa) in a frequency range where $X(\omega)$ has sufficient energy (see Fig. 2) Since $\tau_{c h}$ is unknown a priori, an iteration loop is used to find the correct time delay. Once the correct $\tau_{c h}$ has been found the arrival time is given by:

$$
t_{o a, p}=\tau_{c h}-\frac{\angle X_{c h}\left(\omega_{c}\right)}{\omega_{c}}
$$

The major advantage of this method is that it is not influenced by dispersion and attenuation of the cable. In the absence of complications due to a load impedance $\left(Z_{\text {load }}\right)$ at the cable ends the location error will be zero. Unfortunately, during an online measurement the transmission from cable to load impedance will introduce a phase shift. But, if the characteristic cable impedance and the load impedance are 

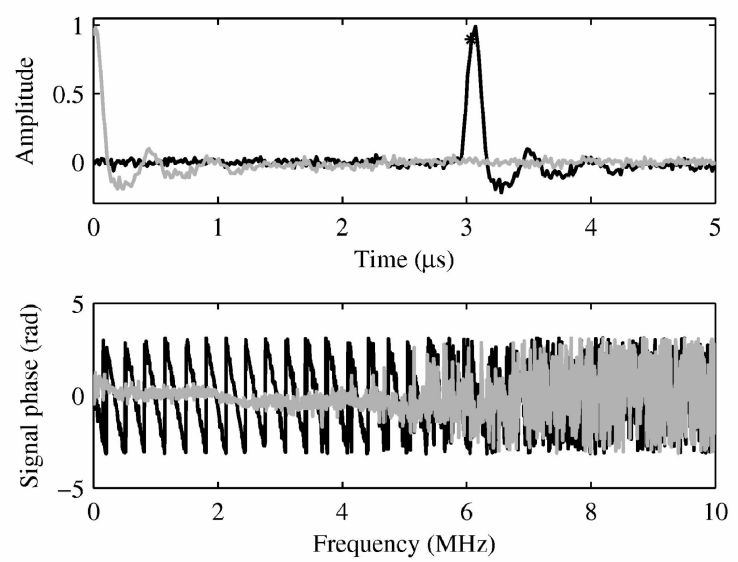

Fig. 2. Signal before and after iteration loop. The signal is plotted in time domain and the phase in frequency domain. The iteration loop ended with $\tau_{c h}=3.05 \mu$ s. Black line: original signal before iteration, gray line: signal after iteration loop, and *: time-of-arrival.

known, e.g. by using an impedance measurement as described in [9], the phase shift can be estimated and $t_{o a, p}$ can be corrected.

\section{PD LOCATION MEASUREMENTS}

For the location of a PD two measurements are required: a cable propagation time $\left(t_{c}\right)$ measurement and the actual PD measurement. Offline diagnostics often uses a single-sided system where the propagation time measurement and PD location are based on reflections from the far end. The impedance of another cable in the RMU connected at the end of the cable under test during online measurements may prevent visible reflections from PD signals. Detection of the pulses at both ends is then preferred [9]. Although the analyses are based on a two-sided system, the conclusions of the $t_{o a^{-}}$ method evaluation are valid for other PD-measurement configurations.

\section{A. Cable propagation time measurement}

The $t_{c}$-measurement using two, non-synchronized measurement systems (one at each cable end) is conducted as follows. A pulse is injected by measurement unit 1 (MU1) at the near cable end $\left(s_{11}\right)$, which is detected by MU2 at the far end $\left(s_{21}\right)$. After a short delay ( $t_{\text {wait }}$, for example $\left.10 \mu \mathrm{s}\right)$ MU2

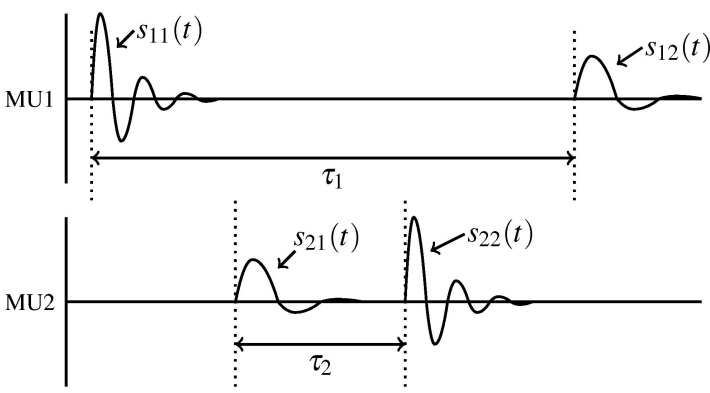

Fig. 3. Signals arriving at both cable ends during a propagation time measurement. injects a similar pulse $\left(s_{22}\right)$, which is detected by MU1 $\left(s_{12}\right)$ The record taken by each unit must contain both pulses. Fig. 3 illustrates schematically the signals recorded by MU1 and MU2.

In the $t_{c}$-measurement there are in total four pulses. The arrival time of each pulse is determined using a $t_{o a}$-method. The time difference between the two pulses recorded by MU1 is given by $\tau_{1}=2 t_{c}+t_{\text {wait }}$, and the time between both pulses of MU2 by $\tau_{2}=t_{\text {wait }}$. The cable propagation time $t_{c}$ is equal to: $t_{c}=1 / 2\left(\tau_{1}-\tau_{2}\right)$. The advantage of this method is that the time bases of MU1 and MU2 do not need to be synchronized for the cable propagation time measurement.

\section{B. PD measurement}

During the PD measurement the measurement units at each cable end detect a PD. The time bases of the units must be accurately synchronized (for example using pulse injection [9] or GPS). The exact arrival time of the PD pulses is determined using one of the $t_{o a}$-methods. The difference in time-of-arrival at both ends is used, together with $t_{c}$, to calculate the PD origin:

$$
z_{P D}=\frac{1}{2} l_{c}\left(1-\frac{t_{o a 2}-t_{o a 1}}{t_{c}}\right)
$$

where $z_{P D}$ is the distance from near cable end to the PD origin, $l_{c}$ the cable length and $t_{o a l}, t_{o a 2}$ the arrival times of the PD pulse at respectively MU1 and MU2.

\section{EXPERIMENTS}

In order to test the methods experimentally, measurements on a test setup have been conducted. The test setup consists of two RMUs with MV/LV transformers and three-core MV Paper Insulated Lead Covered (PILC) cables. A schematic drawing of the test setup is depicted in Fig. 4. The MV cable between RMU1 and RMU2 consists of two different fieldaged cable sections. The propagation velocity of the first section $(96 \mathrm{~m})$ is about $5 \%$ higher than the other section (201 m). RMU1 has a second MV cable that can be disconnected. RMU1 has an MV/LV transformer of 1 MVA, and RMU2 has a transformer of $100 \mathrm{kVA}$. The joint can be opened to inject PD-like pulses with a pulse source. Current probes and injection coils are installed in both RMUs as

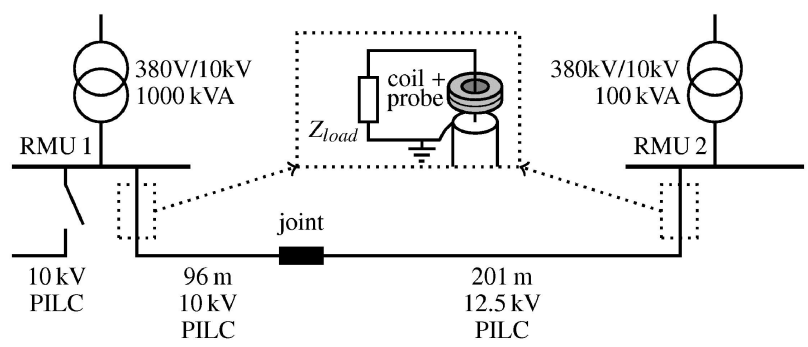

Fig. 4. Schematic drawing of test setup. The insert shows the position of the current probe and injection coil in the RMU 
TABLE 1

MEAN AND STAND ARD DEVIATION OF LOCATION OF EXPER IMENTS. ALL VALUES ARE INM.

\begin{tabular}{l|ccccc}
\hline & Threshold & AIC & EC & Gabor & Phase \\
\hline Exp. 1 & $93.3 \pm 0.8$ & $93.5 \pm 0.6$ & $94.4 \pm 0.6$ & $87.3 \pm 0.3$ & $96.7 \pm 0.3$ \\
Exp. 2 & $94.3 \pm 0.7$ & $94.1 \pm 0.9$ & $93.6 \pm 0.3$ & $121.9 \pm 0.4$ & $82.7 \pm 0.5$ \\
\hline
\end{tabular}

indicated in Fig. 4 (see [9] for details on the installation options).

Two configurations are tested. In the first experiment the parallel cable in RMU1 is disconnected. In both RMUs the load impedance is formed by the transformer and the cables to the transformer. In the second experiment the parallel cable in RMU1 is connected to the rail. The load impedance is now the transformer impedance together with the impedance of the parallel cable. For both configurations first a $t_{c}$-measurement is conducted, followed by a PD measurement where PD-like pulses are injected in the joint. All measurements are repeated 100 times and the results are averaged.

The results of both experiments are listed in Table 1. Equation (7) yields a distance of $93 \mathrm{~m}$ instead of $96 \mathrm{~m}$ due to the difference in propagation speed in the $96 \mathrm{~m}$ section and the $201 \mathrm{~m}$ section. The different propagation velocities can be incorporated in the analysis (see [9]), but for convenience we assume the joint to be at $93 \mathrm{~m}$ and both cable segments to have equal propagation velocities.

The threshold, AIC and EC methods have an accuracy better than $1 \%$ of the cable length in both experiments. The accuracy of the Gabor and (uncorrected) phase methods is insufficient. The accuracy of the phase method can be improved significantly if the load impedances are known around the test frequency $\omega_{c}$, but the results in Table 1 do not take this into account. It intends to simulate the worst-case scenario in which this measurement is not performed accurately or not done at all. During experiment 1 the accuracy of the phase method is reasonable, but during the second experiment the accuracy is definitely insufficient. During the first experiment the load impedances in RMU1 and RMU2 were similar, so the phase shifts cancel, while during experiment 2 the load impedance of RMU1 is changed significantly due to the parallel MV cable. The inaccuracy of the Gabor method is probably caused by reflections present in the signal. The term $t_{k} x_{k}$ in (4) causes reflections coming after the main pulses to have a significant effect on the $t_{o a, g}$.

\section{CONCLUSIONS}

The $t_{\alpha a}$-methods discussed in this paper have been evaluated analytically and compared with simulations elsewhere [5]. The results confirm the experimental verification of the methods presented in this paper. The strong and weak points are summarized in Table 2 are based on the analytical analysis, the simulations and the experiments.

Altogether, no single method performs superior on all criteria. Depending on the situation either the EC method or the phase method will provide the most reliable overall performance. The EC method has good accuracy in most situations. The only point where it failed is on its sensitivity to particular pulse shapes. The strongest point of the phase
TABLE 2

SUMMARY OF STRONG AND WEAK PONTS OF $t_{\alpha \infty}$ METHODS. SEE SECTION II FOR A DESCRIPTION OF THE CRITERIA

\begin{tabular}{c|ccccc}
\hline & Threshold & AIC & EC & Gabor & Phase \\
\hline Noise & - & - & + & 0 & + \\
Pulse shape & $-/ 0^{\mathrm{a}}$ & $-/ 0^{\mathrm{a}}$ & $-/ 0^{\mathrm{a}}$ & $-/ 0^{\mathrm{a}}$ & $+/+^{\mathrm{a}}$ \\
Record length & + & + & 0 & + & + \\
$\begin{array}{c}\text { Pulse location in } \\
\text { record }\end{array}$ & + & 0 & + & + & + \\
$\begin{array}{c}\text { Reflections in } \\
\text { signal }\end{array}$ & + & + & + & - & + \\
Location & + & + & + & - & $-/+^{\mathrm{b}}$ \\
accuracy & & & & & \\
\hline a) by incorpor ating channel's impulse response \\
b) if load impedances are known accurately
\end{tabular}

method is its complete insensitivity to the pulse shape. The second advantage is the high accuracy, provided that the load impedance and characteristic cable impedance can be measured or estimated. If the load impedance is unknown, or if there are other locations in the cable circuit where the phase changes suddenly the accuracy of the phase method is poor.

\section{ACKNOWLEDGMENT}

The author whishes to thank KEMA Nederland B.V. and the Dutch utilities N.V. Continuon Netbeheer, ENECO Netbeheer B.V. and Essent Netwerk B.V. for supporting this research.

\section{REFERENCES}

[1] F. Steennis, P. van der Wielen, B. Kaptein, D. Harmsen, M. Kruithof and A. Postma, "Permanent On-line Monitoring of MV Power Cables Based on Partial Discharge Detection and Localisation - an Update," in Proc. 7th Int. Conf. Insul. Power Cables (Jicable), 2007, paper A 4.1.

[2] H. Zhang, T.R. Blackburn, B.T. Phung and D. Sen, "A Novel Wavelet Transform Technique for On-line Partial Discharge Measurements Part 1: WT De-noising Algorithm," IEEE Trans. Dielectr. Electr. Insul, vol. 14(1), pp. 3-14, 2007

[3] Y. Zhou, Y. Qin P. Chappell, "Cost-Effective On-line Partial Discharge Measurements for Cables," IEEE Electr. Insul. Mag., vol. 22(2), pp. 31 38,2006

[4] M. Michel, "Innovative asset management and targeted investments using on-line partial discharge monitoring \& mapping techniques," in Proc. Int. Conf. Electr. Distr. (CIRED), 2007, paper nr. 0551.

[5] P. Wagenaars, P.A.A.F. Wouters, P.C.J.M. van der Wielen and E.F. Steennis, "Accurate Estimation of the Time-of-Arrival of Partial Discharge Pulses in Cable Systems in Service," submitted for publication.

[6] C. Herold, T. Leibfried, S. Markalous, and I. Quint, "Algorithms for automated arrival time estimation of partial discharge signals in power cables," in Proc. Int. Symp. High Volt. Eng. (ISH), 2007, paper T7-332.

[7] R. Sleeman and T. van Eck, "Robust automatic p-phase picking: an online implementation in the analysis of broadband seismogram recordings," Phys. Earth Planet. Inter, vol. 113, pp. 265-275, Jun. 1999.

[8] D. Gabor, "Theory of communication," J. IEE Pt. III: Radio Commun. Eng., vol. 93, pp. 429-457, Nov. 1946.

[9] P.C.J.M. van der Wielen, "On-line detection and location of partial discharges in medium-voltage power cable," Ph.D. dissertation, Eindhoven University of Technology, Eindhoven, The Netherlands, 2005. [Online]. Available: http:/www tue .nl 